Reference: Sellers, R., \& Nicolau, J. L. (2021). Satisfaction and Expenditure in Wineries: A Prospect Theory Approach. Journal of Hospitality \& Tourism Research, 10963480211031407.

\title{
SATISFACTION AND EXPENDITURE IN WINERIES: \\ A PROSPECT THEORY APPROACH
}

\author{
Ricardo Sellers \\ Department of Marketing \\ Faculty of Economics \\ University of Alicante \\ PO Box 99 \\ 03080 Alicante \\ Spain \\ e-mail: ricardo.sellers@ua.es
}

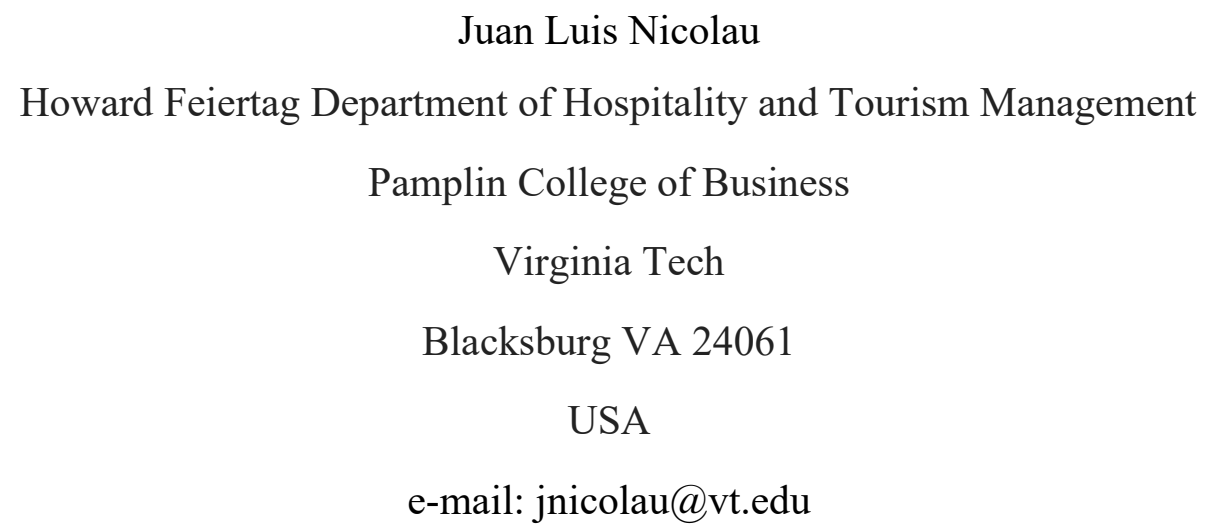

Acknowledgement: This work was partially supported by the Spanish Ministry of Science, Innovation and Universities under research project INTETUR (RTI2018-099467-B-I00). 


\title{
SATISFACTION AND EXPENDITURE IN WINERIES: \\ A PROSPECT THEORY APPROACH
}

\begin{abstract}
Visitor satisfaction has been shown to be a critical determinant of visitor expenditure in wineries. Although the relationship between visitor satisfaction and expenditure in wineries has been investigated in previous literature, we have unearthed potential intricacies that emerge when this relationship is analyzed within the reference dependence framework of prospect theory. To fill this gap, we use segment-based reference points to capture the singularity of winery visitors, and results show that demographics and psychographics confirm reference dependence. When reference points are based on psychographics, loss aversion is confirmed (lowering visitor satisfaction has a greater negative impact on expenditure than the positive impact derived from increasing visitor satisfaction), while diminishing sensitivity is observed for losses (the effect of the variations in visitor satisfaction shifts depending on the distance from the individual's reference point). Interestingly, when the reference points are obtained through demographics, loss aversion is reversed. Relevant managerial implications are outlined.
\end{abstract}

Keywords: satisfaction; expenditure; winery; loss aversion; prospect theory. 


\section{INTRODUCTION}

Wineries are mostly visited by wine enthusiasts and people who are interested in wine regions (Charters \& Ali-Knight, 2002). On account of the impact of this experience on wineries and its subsequent potential spillover effect on the region, analyzing the behavioral patterns of winery visitors is critical (Bruwer et al., 2018). Chief among these behavioral patterns is the relationship between winery visitor satisfaction and winery visitor expenditure. The effects of satisfaction on behavioral dimensions, such as visitor expenditure, have been investigated in previous literature (Mitchell \& Hall, 2004; O’Neill et al., 2002; Lee et al., 2018). In this article, we attempt to unearth the potential intricacies that can emerge in the relationship between winery satisfaction and expenditure within a reference dependence framework (Kahneman \& Tversky, 1979). This is certainly a gap in the literature that we attempt to fill that can provide relevant implications, both theoretical and managerial. Reference dependence is based on the two main tenets of prospect theory: i) loss aversion, through which losses have a larger effect than gains (e.g., finding a lower than expected level of satisfaction can result in a bigger effect on expenditure than getting a higher than expected level of satisfaction); and ii) diminishing sensitivity, through which a change in a variable (e.g., satisfaction) has a different effect depending on how far away this change occurs from people's benchmark.

Winery visits can be a major source of revenue for wineries because they present a way to sell their products directly to the consumer (Kolyesnikova et al., 2007). From a marketing viewpoint, wineries can regard the influx of visitors as a learning opportunity for consumers and an avenue to build a strong brand image not only for wineries but also for the regions in which these wineries are located. In this context, understanding, in general, the behavior of winery visitors is crucial to achieve the benefits of the influx (Yuan et al., 2005), and in particular, the way 
satisfaction has an influence on expenditure is critical to take advantage of the increasing interest in wineries (Lee et al., 2018).

The growing attraction to wineries can affect the regions in which these wineries are located. As a form of tourism, Hall et al. (2000, p. 3) broadly defined wine tourism as a "visitation to vineyards, wineries, wine festivals, and wine shows, for which grape wine tasting and/or experiencing the attributes of a grape wine region are the prime motivating factors for visitors."

Generally, studies on wine tourism have addressed one of the following three topics (Thanh \& Kirova, 2018). First, studies have discussed the destinations' strategies, which includes examining the initiatives that reinforce the promotion of wine tourism destinations, the costbenefit analysis of wineries, and its effects on the image of the destination (Hojman \& HunterJones, 2012). Second, research has been centered on the players that act in the wine tourism industry and on the strategies followed by wineries (Dawson et al., 2011). For example, Veres et al. (2008) have highlighted the relevance of setting up tasting rooms at wineries, in which wine education is further cultivated, and Thomas et al. (2016) have examined the "servicescape" of wineries. Third, research has also examined the visitors' perspective, such as aiming to characterize the profiles of winery visitors (Charters \& Ali-Knight, 2002; Lee et al., 2018). This body of research has also looked into winery visitors' segmentation (Mitchell \& Hall, 2006; Alonso et al. 2007). Other topics have considered the drivers - among which satisfaction plays a significant role (Mitchell \& Hall, 2006) — that motivate consumers to opt to visit wineries and the analysis of the dimensions that can anticipate behavioral outcomes (Carlsen and Boksberger, 2015, Ye et al., 2017; Lee et al., 2018).

Taking the latter two elements (visitor satisfaction and behavioral outcomes), the purpose of this article is to analyze the effect of satisfaction on a critical outcome, namely, the expenditure of 
visitors in the winery. While the literature has explored the relationship between these two dimensions, we argue that in a reference dependence framework, the effect of satisfaction on expenditure can reveal hidden relationships that are otherwise unobservable. Based on prospect theory (Kahneman \& Tversky, 1979), we propose a reference dependence model, in which the two basic principles of this theory, namely, loss aversion and diminishing sensitivity, are introduced. For this purpose, we generate the segment-based reference points (rather than the traditional product-based reference points) to capture the singularity of winery visitors.

\section{DETERMINANTS OF CONSUMER EXPENDITURE IN WINERIES}

To understand the winery visitors' behavior and their level of spending, determining the key factors of the winery experience that drive this expenditure is critical. Previous literature has highlighted that the profiling and segmentation of winery visitors should be a priority owing to its relevance to the strategies of wineries (Lee et al., 2018; Cho et al., 2018). In this literature on segmentation, two approaches can be used to segment the winery visitors' market (Mitchell \& Hall, 2006; Del Chiappa et al., 2019): demographic characteristics, such as gender, age, or income, and psychographic characteristics, such as motivations, values, attitudes, or lifestyles. In the context of wineries, wine knowledge and interest are also frequently considered (Rahman and Reynolds, 2015).

The importance of demographic variables has been strongly supported in the literature to explain winery visitor behavior. For example, Dodd and Bigotte (1997) defined two groups of winery visitors according to their age and income level. Alonso et al. (2007) found various expense levels for distinct age groups, stating that a high income does not correlate with high expenditure. Mitchell and Hall (2001a) stated that differences exist between winery visitors in 
terms of gender. They found that females give importance to the ambience of the winery and socializing opportunities. Marzo-Navarro and Pedraja-Salinas (2010) proposed various market segments based on demographics that can lead to distinct consumption patterns. Given their objective nature, demographic variables can facilitate the identification of consumers and implement marketing strategies (Charters \& Ali-Knight, 2002).

On the other hand, although psychographic variables may explain—better than demographicsthe behavior of winery visitors, their subjective nature represents a big challenge for companies which wish to use psychographics for strategic planning (Molina et al., 2015). The importance of psychographic characteristics has been previously addressed to segment winery visitors and to explain their behavior (Barth \& Salazar, 2010). According to previous literature, two productrelated psychographic variables are critical in determining the winery visitors' behavioral patterns: i) Interest in wine, which is strongly related to wine involvement, which is a central construct in the analysis of consumer behavior that may affect the decision to purchase a product (Hollebeek et al., 2007). For example, Hollebeek et al. (2007) found that consumers who are heavily engaged in the winery experience attribute great relevance to the region where the wine is produced while being less sensitive to price; Charters and Ali-Knight (2002) observed a link between the degree of interest in wine and people's motivation to go to wineries; and Nella and Christou (2014) classified winery visitors into three segments, namely, low, medium and high involvement, revealing that the assessment of the winery experience and wine purchases are contingent upon this classification; ii) Knowledge of wine, which refers to the "familiarity that a consumer has with a product" (King et al., 2012), and has been used to segment wine consumers (e.g., Bruwer \& Buller, 2012). For example, Alonso et al. (2007) found evidence of the 
differences among winery visitors based on their wine knowledge. They observed that visitors with greater wine knowledge than others exhibit higher spending after the visit.

Apart from demographics and psychographics, satisfaction — as a third element—emerges as a critical explanatory dimension of the consumption behavior of winery visitors in terms of expenditure (O'Neil et al., 2002; Mitchell \& Hall, 2004; Lee et al., 2018; Thanh \& Kirova, 2018). These authors emphasize this connection in the context of winery visitors on account of its experiential character. In the winery experience, the senses have played a central role in providing visitors with enjoyment (Getz, 2000). Hence, certain authors have focused their attention on the customer experience (Bruwer \& Alant, 2009). By focusing on the effect of consumer satisfaction on purchase behavior, the underlying idea is that wineries usually offer a holistic experience that may influence consumer behavior during the visit (Mitchell \& Hall, 2004) and after the visit (O’Neill et al., 2002). In this sense, Bruwer and Alant (2009) and Mason and Paggiaro (2012) have emphasized the need to consider satisfaction as a central construct because satisfaction driven by the whole winery experience may affect behavior. Moreover, Back et al. (2019) and Leri and Theodoridis (2019) have found that the intention to visit the winery is determined by visitor satisfaction, and Park et al. (2019) have also observed that satisfaction has a moderating effect on revisit intentions; in particular, these authors found that, while there is a point of satiation after which revisit intentions start to lower, this satiation point (measured by the number of optimal visits) becomes higher as satisfaction increases.

Although the effect of satisfaction on the winery visitors' consumption has been studied and is well-established in the existing literature, we go a step further and analyze the potential intricacies that can be uncovered when this effect is set in the reference dependence framework provided by prospect theory. In fact, our central explanatory variable, for which this article states 
its hypotheses, is the level of satisfaction in the context of prospect theory. Thus, once we have reviewed the effects of demographics and psychographics in order to provide the framework in which the hypotheses are developed, we next justify and state the satisfaction-related hypotheses in the reference dependence framework of prospect theory.

Effect of winery visitor satisfaction on expenditure in a reference dependence framework.

According to prospect theory (Kahneman \& Tversky, 1979), people's assessment tends to be reference-dependent because they compare the performance of a service to a benchmark. The consequence of these discrepancies is the existence of potential hidden effects on a specific outcome (e.g., level of expenditure). Specifically, within reference dependence of prospect theory there are two central characteristics: i) loss aversion, which indicates that negative discrepancies (losses) have a larger effect than positive differences (gains) (e.g., the effect derived from finding the experience in a winery less satisfactory than expected will have a bigger effect on the level of expenditure than finding that experience more satisfactory than expected); and ii) diminishing sensitivity, which entails that a given increment (or decrement) in a variable (satisfaction) has a different effect depending on how far away this increment occurs from people's benchmark.

Various applications in hospitality and tourism have utilized the tenets of prospect theory. Nicolau (2008) has tackled the prices in various types of tourism products, Kim and Canina (2015) have examined satisfaction in travel destinations, $\mathrm{Xu}$ (2019) has compared hotel attributes with customer satisfaction, and Chattopadhyay and Mitra (2020) have examined the determinants of the peer-to-peer tourist accommodation price. However, no analysis has been conducted in the 
context of wineries. The potential effects of prospect theory in the context of winery visits is unique, as we can discover relevant intricacies in the relationship between satisfaction and expenditure in a framework in which numerous winery visitors are considered "wine experts" or at the very least, "wine lovers". Thus, their degree of satisfaction compared to their reference group should have an effect on an outcome variable, such as expenditure. Hence, this article attempts to investigate whether obtaining a higher (or lower) level of satisfaction than that of an individual's reference group, which is defined via demographics or psychographics, has a distinct effect on expenditure when visiting a winery.

On account of the arguments based on prospect theory, we expect the deviations of satisfaction from the individual's reference group, regardless of whether this group is defined in demographic or psychographic terms, to explain the level of consumer expenditure when visiting a winery. Consequently, we propose the following hypotheses:

H10 The effect of winery visitor satisfaction on expenditure is not reference-dependent. H1 a The effect of winery visitor satisfaction on expenditure is reference-dependent.

While demographics and psychographics can capture the various personality traits of a person, we expect that the standard properties of prospect theory, i.e., loss aversion and diminishing sensitivity, can apply to the relationship between satisfaction and expenditure. Accordingly, the following hypotheses are stated as follows:

H20 Lower than expected satisfaction does not bring a negative impact on winery visitor expenditure that is higher than the positive impact derived from higher than expected satisfaction. 
H2 $\mathbf{a}_{\mathbf{a}}$ In line with the loss aversion principle, lower than expected satisfaction brings a negative impact on winery visitor expenditure that is higher than the positive impact derived from higher than expected satisfaction

H3 ${ }_{0}$ Changes in satisfaction that are closer to the reference point will not cause a larger impact on visitor expenditure than changes in satisfaction that are further away from reference points.

H3a In line with the diminishing sensitivity principle, changes in satisfaction that are closer to the reference point will cause a larger impact on visitor expenditure than changes in satisfaction that are further away from reference points.

\section{RESEARCH DESIGN}

Sample and variables

To gather the data required for this paper, an online survey was conducted in Spanish using the Qualtrics (www.qualtrics.com) platform. The population of interest was comprised of people who had visited a Spanish winery. All respondents were adults that had visited at least one winery in the last 24 months. Respondents that had visited more than one winery for the past 24 months were instructed to think only about their most recent winery visit. We pre-tested the questionnaire on a sample of five face-to-face interviews and five online respondents. The survey was conducted between April 1st and April 21st, 2019 and was promoted through the Spanish Association of Wine Tourism (www.enoturismodeespaña.es), Vinetur (www.vinetur.com), and social networks (Twitter and Facebook). We collected 524 responses. We discarded 79 questionnaires because respondents had not visited a winery in the last 24 months and 18 questionnaires due to incomplete responses. The final sample comprised 427 participants. 
Spain is arguably an adequate study field because not only is the country one of the world's top destinations (UNWTO, 2019) but also one of the world's largest wine producers (OIV Report, 2019). Wineries view this synergy between tourists, visitors, and wine as a great opportunity for their development (Marzo-Navarro \& Pedraja-Iglesias, 2012).

To make the reference dependence model operative, we defined the following dependent and independent variables, whose descriptive statistics are shown in Table 1.

1) Dependent variable. The level of expenditure in the winery is the money spent by the consumer during the visit, which was measured through a quantitative variable. As this information relies on respondents' memory, it can be biased; nevertheless, the average of this variable (€17.67) is very similar to the amount (€18.27) reported by Acevin (2018) for 2017.

2) Independent variables. The central variable is satisfaction, which was measured through three items in the questionnaire, in which the visitors reported their degree of satisfaction with the following three dimensions of the visit using a 7-point Likert scale: staff, winery facilities, and landscape and environment. With regard to the two psychographic variables, "interest in wine" was measured through the following four items: I often attend wine tastings; Wine culture should be promoted more intensely; I read wine magazines; and I am interested in wine. "Wine knowledge" was measured through the following three items, in which the visitors expressed their degree of agreement or disagreement using a 7-point Likert scale: I am a wine specialist, I know different wine areas (protected designations of origin), and I have a broad knowledge of wine culture. These psychometric scales are adapted from Molina et al. (2015) and MarzoNavarro and Pedraja-Iglesias (2010). For these variables, an overall mean of the different items was used to measure the participants' satisfaction (Cronbach's alpha $=0.749$ ), interest in wine (Cronbach's alpha $=0.881$ ), and wine knowledge (Cronbach's alpha $=0.773$ ). In terms of 
reliability, we obtained the acceptable values of the Cronbach's alpha because all of them were greater than the generally accepted threshold of 0.70 .

As for demographic variables, the following characteristics were obtained: i) age of the consumer, which was measured through a categorical variable: $18-24,25-34,35-44,45-54$ and

older than 55; ii) gender, measured by a dummy variable that takes the value 1 if the consumer is male and 0 otherwise, and iii) income, which was measured through a categorical variable representing the consumer's monthly income expressed in euros (lower than $€ 900$, between $€ 900$ and $€ 1500, € 1501-€ 2000, € 2001-2500$, and greater than $€ 2501)$.

\section{[Insert Table 1 about here]}

\section{Research instrument}

To test the reference dependence via loss aversion and diminishing sensitivity in consumer expenditure in wineries, we introduced the basic characteristics proposed in prospect theory (Kahneman \& Tversky, 1979) into a regression model, which is expressed as follows:

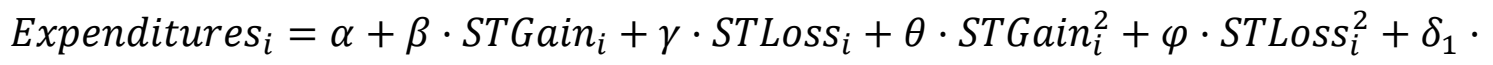
Knowledge $_{i}+\delta_{2} \cdot$ Interest $_{i}+\mu_{1} \cdot$ Age $_{18-34, i}+\mu_{2} \cdot$ Age $_{>45, i}+\rho_{4} \cdot$ Gender $_{i}+\tau_{1}$. $_{\text {nen }}$ Income $_{<€ 1501, i}+\tau_{2} \cdot$ Income $_{>€ 2001, i}+\varepsilon_{i}$,

where Expenditures E $_{i}$ is the amount of money spent in the after-visit purchase. STGain is $_{i}$ the "gain in satisfaction," which is defined as (Actual Satisfaction ${ }_{i}$-Expected Satisfaction $) \cdot D_{l}$, where $D_{1}=1$ if $\left(\right.$ Actual Satisfaction $_{i}$ - Expected Satisfaction $\left.{ }_{i}\right)>0$ and $D_{1}=0$ otherwise. STLoss $i$ is the "loss in satisfaction," which is defined as (Actual Satisfaction ${ }_{i}$ - Expected Satisfaction E $_{i}$. $D_{2}$, where $D_{2}=1$ if $\left(\right.$ Actual Satisfaction $_{i}$ - Expected Satisfaction $)<0$ and $D_{2}=0$ otherwise. The psychographic variables are Knowledge $_{i}$ and Interest $t_{i}$ and the demographic variables are age $e_{i}$ (for the sake of parsimony in the number of parameters, the two extreme categories on each side 
are grouped and the central category (age 35-44) is the baseline), gender ${ }_{i}$ and income $_{i}$ (as before, the extreme categories are grouped and the central category (Income $€ 1501-€ 2000$ ) is the baseline). $\varepsilon_{i}$ is a random term. In addition, $\alpha, \beta, \gamma, \theta, \varphi, \delta_{1}, \delta_{2}, \mu_{j}(j=1, \ldots, 4), \rho$ and $\tau_{j}(j=1, \ldots, 4)$ are the parameters of the model.

If the parameter associated with "loss in satisfaction" was greater than the parameter related to "gain in satisfaction" $\left(\gamma_{i} / \beta_{i}>1\right)$, a loss aversion was confirmed. If the parameter associated with the square of "gain in satisfaction" was significantly negative $(\theta)$ and the parameter related to the square of "loss in satisfaction" was significantly positive $(\varphi)$, then the diminishing sensitivity was confirmed. The parameters $\delta_{j}, j=1, \ldots, 5$ are associated with the two psychographics and the three demographics.

As indicated previously, the "expertise" of numerous winery visitors made the context of this study unique. Specifically, one of its singularities is the reference point we should use. Rather than using the product-based benchmarks prevalent in the literature (Kim and Canina, 2015), we could resort to segment-based reference points to capture the differences between the individual's satisfaction and his or her comparison group to analyze the effects of these differences. In line with the literature on winery experiences, which emphasized the use of demographic and psychographic segmentations (Mitchell \& Hall, 2006), we generated two comparison groups for each individual.

To calculate the expected satisfaction, we identified the potential segments in the sample and calculated the average satisfaction of each segment. This average was used as the expected satisfaction of the comparison group that the visitor belonged to. We utilized the Ward hierarchical cluster analysis algorithm, which was applied to the demographics (age, gender, and income) and the psychographics (knowledge and interest) separately to obtain the optimal 
number of segments for each type of characteristics. According to Lewis and Thomas (1990), the optimal number of segments was obtained when the segments observed could explain at least $65 \%$ of the global variance, whereas the increase in the total variance derived from adding a new segment was more than 5\%. From each of the two segmentations (demographics vs. psychographics), the average value of satisfaction for each segment would be obtained and used as the expected value of the individual's comparison group.

\section{RESULTS AND DISCUSSION}

Prior to proceeding with the parameter estimates, certain statistics controls were required. First, we estimated the variance inflation factors, in which no parameter exceeded the value of 10 . Consistent with Neter et al. (1989), collinearity did not seem to be an issue. Still, given that in this preliminary analysis we detected a high correlation of $78.5 \%$ between the variables "interest in wine" and "knowledge of wine", we then separated these variables when estimating the models. Second, the Breusch-Pagan test rejected homoskedasticity $(F=2.816$; p-value $<0.01$ and $F=2.616 ; \mathrm{p}$-value $<0.05)$. Therefore, the White heteroskedasticity standard errors were calculated for the parameter estimates. Finally, we tested for the sample selection bias, which was critical for this application. Sample selection bias could emerge when analyzing the factors that explained the expenditure of a winery visitor because this expenditure was only observed if an individual decided to buy something after the visit. However, the expenditure was unobservable otherwise. Not controlling for this bias could result in spurious parameter estimates. Following the sample selection correction proposed by Heckman (1979), we introduced inverse Mill's ratio $\left(I M R_{i}\right)$ in the following baseline models: 
Expenditures $_{i}=\alpha+\tau \cdot$ Satisfaction $_{i}+\delta_{1} \cdot$ Knowledge $_{i}+\mu_{1} \cdot$ Age $_{18-34, i}+\mu_{2} \cdot$

Age $_{>45, i}+\rho_{4} \cdot$ Gender $_{i}+\tau_{1} \cdot$ Income $_{<€ 1500, i}+\tau_{2} \cdot$ Income $_{>€ 2001, i}+\psi_{1} \cdot \operatorname{IMR}_{i}+\varepsilon_{i}$,

Expenditures $_{i}=\alpha+\tau \cdot$ Satisfaction $_{i}+\delta_{2} \cdot$ Interest $_{i}+\mu_{1} \cdot$ Age $_{18-3, i}+\mu_{2} \cdot$ Age $_{>45, i}+$

$\rho_{4} \cdot$ Gender $_{i}+\tau_{1} \cdot$ Income $_{<€ 1500, i}+\tau_{2} \cdot$ Income $_{>€ 2001, i}+\psi_{2} \cdot$ IMR $_{i}+\varepsilon_{i}$,

The results showed that the parameter $\psi$ associated with the IMR was insignificant in either equation. $\psi_{1}$ was $6.278(\mathrm{t}=0.565 ; \mathrm{p}$-value $=0.572)$, and $\psi_{2}$ was $7.347(\mathrm{t}=0.696 ; \mathrm{p}$-value $=$ 0.487). These insignificant values meant that sample selection bias should not be an issue in this empirical application. Technically, this result showed that we could not reject the null hypothesis that the error terms of the expenditure equation and the purchase equation were uncorrelated. Thus, as our data were consistent with no selection, we could use the standard regression model. In fact, we re-estimated the previous two models without the $I M R$, and we obtained slightly better values on the Schwarz information criterion, which were 8.532 versus 8.552 and 8.433 versus 8.453 .

Once we checked for collinearity, heteroskedasticity, and sample selection bias, we proceeded with the estimation of the models with reference dependence. For this purpose, we need to estimate the reference points (expected satisfaction) for each individual. The application of the Ward hierarchical cluster analysis algorithm, along with Lewis and Thomas' (1990) criteria ( $65 \%$ of global variance and a minimum increase of $5 \%$ when adding a new segment), showed that the optimal number of segments based on demographics and psychographics were six and five, respectively (see Tables 2 and 3). For each of these segments, we calculated the average value of satisfaction (Table 4), which was representative of the expected value of the individual's comparison group. The introduction of these variables allowed us to estimate the results presented in Table 5 . 


\section{[Insert Tables 2, 3 and 4 about here]}

Models 1 and 2 in Table 5 show the effect of satisfaction on winery visitor expenditure, in which the values of the comparison groups (expected satisfaction) are obtained through psychographics. Models 3 and 4 present the effect of satisfaction on winery visitor expenditure, in which the values of the comparison groups (expected satisfaction) are obtained through demographics. Models 1 and 3 include the variable "interest in wine" whereas excluding "knowledge of wine." The reverse applies to Models 2 and 4 . We observed that the models with expected satisfaction based on psychographics (Models 1 and 2) have slightly better R-squared measures than the models with expected satisfaction based on demographics (Models 3 and 4); the models that include "interesting in wine" (Models 1 and 3) show better R-squared measures than those that include "knowledge of wine" (Models 2 and 4). The parameter estimates of Models 1 and 2 are robust in terms of significance and sign, as are the parameters of Models 3 and 4.

\section{[Insert Table 5 about here]}

Models 1 and 2 where the expected satisfaction is obtained through psychographics. We found that the parameters associated with loss in satisfaction (STLoss) and with the squared of loss in satisfaction $\left(S T L O \operatorname{Lss}^{2}\right)$ were significant and positive. The fact that we obtained significant parameters that capture reference dependence supported the alternative Hypothesis $1_{\mathrm{a}}$, which posited that the effect of winery visitor satisfaction on expenditure was reference dependent in line with Kahneman and Tversky's (1979) prospect theory. Interestingly, the parameters related to the gain in satisfaction (STGain) and the squared of gain in satisfaction $\left(\right.$ STGain $\left.^{2}\right)$ were noninsignificant. As the loss parameter was significantly greater than zero, we could state that it was also significantly greater than the non-significant gain parameter. The result that the loss parameter is greater than the gain parameter was consistent with the loss aversion principle of 
Kahneman and Tversky's (1979) prospect theory and with the alternative Hypothesis 2 a. Accordingly, this outcome shows that lower than expected satisfaction brings a negative impact on winery visitor expenditure; and this negative impact on expenditure is greater than the positive impact derived from higher than expected satisfaction. This loss aversion meant that a reduction in satisfaction by an amount $s$ would lead to a decrease in winery expenditure greater than the increase in winery expenditure, which were derived from an augment in satisfaction by an equivalent amount $s$. In practical terms, the insignificant gain parameter indicated that getting more satisfaction than the one expected in the individual's psychographic comparison group did not lead to an increase in expenditure. However, given the significant loss parameter, getting less satisfaction than what was expected for the individual's psychographic comparison group caused a significant reduction in expenditure.

With regard to the results obtained for the square variables, namely, STGain ${ }^{2}$ and $S T L o s s^{2}$, the fact that the latter was significant and positive whereas the former was insignificant indicated that the diminishing sensitivity was only observed for losses. Consequently, these results are in line with the alternative Hypothesis $3 \mathrm{a}$ as changes in satisfaction that were closer to the reference point would cause a larger impact on visitor expenditure than changes in satisfaction further away from reference points. This result was only observed in loss in satisfaction (not for gain in satisfaction). The distance from an individual's level of satisfaction did not seem to have any effects. This parameter was unsurprisingly insignificant because, as shown earlier, the gain parameter itself was also insignificant.

These types of departures from the prospect theory are not unusual in the hospitality and tourism literature. For example, the same pattern as the one found in this application (loss aversion and 
diminishing sensitivity for losses) has also been observed in the context of reference prices by Nicolau (2008). These kinds of anomalies can offer new insights into consumer behavior.

Models 3 and 4 where the expected satisfaction is obtained through demographics. We found that only the parameter associated with gain in satisfaction (STGain) was significant. Although a different pattern was observed in this case compared with the previous one, these results can still support the alternative Hypothesis $1_{\mathrm{a}}$ because one reference dependence parameter was significant.

However, the parameters related to loss in satisfaction (STLoss), squared of loss in satisfaction $\left(S T \operatorname{Loss}^{2}\right)$ and squared of gain in satisfaction $\left(\right.$ STGain $\left.^{2}\right)$ were insignificant. These results did not support alternative Hypotheses $2_{\mathrm{a}}$ and $3_{\mathrm{a}}$, thus favoring null hypotheses $2_{0}$ and $3_{0}$. The fact that the gain parameter was significant and was greater than the insignificant loss parameter was against the loss aversion principle. This result showed evidence of a reversed loss aversion, which was consistent with the results found in other applications (Walasek \& Stewart, 2015; Zheng et al., 2018). This finding indicates that an increment in satisfaction by an amount $s$ would lead to an increase in winery expenditure, which would be greater than the decrease in winery expenditure derived from a reduction in satisfaction by an equivalent amount $s$. In practical terms, the significant gain parameter indicated that obtaining more satisfaction than the one expected in the individual's demographic comparison group led to an increment in expenditure greater than the one obtained under lower satisfaction. However, given the insignificant loss parameter, obtaining less satisfaction than the expected for the individual's demographic comparison group did not cause a significant reduction in expenditure.

On the other hand, the insignificant parameters obtained for the square variables, STGain ${ }^{2}$ and STLoss ${ }^{2}$, were against diminishing sensitivity. Thus, the impact of variations in satisfaction was 
independent of how close or far away from the reference point the individual's level of satisfaction was.

Consequently, considering the distinct effects of demographics and psychographics outlined in the literature review, both types of characteristics seemed to capture various personality traits of a person. Thus, the definition of the individual's comparison groups had an influence on the effect of satisfaction on visitor expenditure. For psychographic comparison groups, loss aversion and diminishing sensitivity for losses were observed. By contrast, loss aversion was reversed, and the diminishing sensitivity was absent in demographic comparison groups.

With regard to the control variables, consistent estimates were found for all four models. "Interest in wine" (Models 1 and 3) and "knowledge of wine" (Models 2 and 4) were significant and positive, which meant that the more interested in wine and more knowledgeable about wine people were, the more they would buy after visiting the winery. Interest in wine is a key construct in consumer behavior research, and several authors have highlighted the link between wine involvement and purchase/consumption (Rahman \& Reynolds, 2015). Our results supported this idea in the sense that the interested consumers would spend more money after their visit. The positive relationship between "knowledge of wine" and expenditure found in this article was consistent with Mitchell and Hall's (2001b) research, in which wine knowledge was linked to monthly wine expenditure. With regard to the "age", "gender," and "income", only "gender" was significant, thus indicating that male visitors tended to spend more money on purchasing wine after their visit than female visitors; this finding was consistent with that of Bruwer et al. (2013).

CONCLUSIONS AND IMPLICATIONS 
Even though the effects of satisfaction on behavioral dimensions, such as visitor expenditure, have been investigated in previous literature (Lee et al., 2018), this article unearths some intricacies that can emerge in the satisfaction-expense relationship within the reference dependence framework provided by prospect theory. Therefore, this article has filled this gap by introducing loss aversion and diminishing sensitivity in the model proposed. The empirical application allows us to draw the following conclusions:

1) Differentiated patterns of reference dependence between visitor satisfaction and winery expenditure are found in comparison groups, which are defined by demographics versus psychographics. Both characteristics can lead to reference dependence (at least one reference dependence parameter is significant). However, they can pick up different elements of winery visitors. Furthermore, their expectation of satisfaction may vary depending on the comparison group that is used.

2) In the models wherein the expected satisfaction has been obtained through psychographics, the variables that seem to have an impact on visitor expenditure are "loss in satisfaction" and the "squared of loss in satisfaction". Consequently, the loss aversion is confirmed (lowering visitor satisfaction has a greater negative impact on expenditure than the positive impact derived from increasing visitor satisfaction), and the diminishing sensitivity is observed for losses (the effect of a variation in visitor satisfaction shifts depending on the distance from the individual's reference point).

3) In the models wherein the expected satisfaction has been obtained through demographics, the variable that seems to have an effect on visitor expenditure is "gain in satisfaction". Given that the gain parameter is significantly greater than the loss parameter, a reversed loss aversion is 
found (the increment in expenditure derived from obtaining greater satisfaction was larger than the reduction in expenditure derived from lower satisfaction).

With regard to the theoretical contributions, several theoretical implications are to be considered: i) introducing the reference dependence in satisfaction measures when modeling the behavioral outcomes, such as expenditure, can shed new insights in the satisfaction-expense relationship (although the literature has dealt with this relationship in the context of wineries, the inclusion of reference dependence has allowed us to uncover new effects of satisfaction on expenditure). ii) The use of segment-based reference points (rather than the traditional product-based reference points) has proven to be effective in detecting different patterns in the satisfaction-expense relationship. Stemming from the prevalent distinction between demographic and psychographic segmentations that the literature on winery visitors has established, two types of benchmarks have been generated (psychographic segment-based reference points and demographic segmentbased reference points) to capture the different traits of consumers.

Several managerial implications have been pointed out, such as: 1) comparing consumer satisfaction with the expected satisfaction of the comparison group to which the consumer belongs can add relevant insight to the expenditure patterns. Rather than just considering satisfaction levels as absolute measures, regarding these levels as relative measures is relevant to decision makers. Notably, the results from this research (in which the reference points are derived from an individual's comparison group) offer a new angle on the satisfaction in winery visitors.

2) When the customer base of a winery is defined in terms of psychographics, loss aversion can emerge. Therefore, when the service provided by a winery fails to fulfill the consumers' expectations, this loss aversion means that the negative impact on expenditure is greater that the 
positive impact of an increase in satisfaction of the same amount. For instance, a decrement in the rating of satisfaction from 6 to 5 (in a 7-point Likert scale) can be perceived as a decrease in the quality of service, which influences expenditure. If managers can solve this quality reduction and attempt to raise the satisfaction to 6 , the increment from 5 to 6 will not produce the same size of variation (with a different sign) in expenditure as the previous decrement. The variation in satisfaction from 5 to 6 will cause a lower positive impact on expenditure than the negative impact derived from the variation from 6 to 5 . Hence, the pragmatic consequence is that the "efforts" to obtain the satisfaction back to the previous upper levels must be greater than the "distraction" that caused the reduction in satisfaction.

3) For wineries that define their market segment in accordance with psychographics, diminishing sensitivity will protect a winery's reputation (materialized by high levels of satisfaction) from service failures than wineries with lower levels of satisfaction. For psychographic-related reference points, the diminishing sensitivity has been found for losses. In practical terms, if the service received is worse than expected, variations in satisfaction further away from the reference point will result in lower marginal impacts than equivalent variations closer to the reference point. The negative impact of bad experiences on expenditure will be lower if the satisfaction changes from 6 to 5 than if the satisfaction level shifts from 3 to 2 . Therefore, in the event of a service failure, wineries with high and low levels of satisfaction must try their best to implement service recovery strategies. However, wineries with high levels of satisfaction may have some leeway (assuming that the service failure is not major), whereas wineries with low levels of satisfaction need to work hard to solve issues and compensate its customers because the negative influence of a bad experience can reduce the consumer expenditure of these wineries. 
4) For wineries that define their market segment through demographics (in which reversed loss aversion is found), strategies and tactics seem to be less complex than for wineries that use psychographics. The fact that the variable "gains in satisfaction" brings an increment in expenditure that is greater than the decrement derived from "losses in satisfaction" has given these wineries some advantage. For the demographic-based segment, despite the logical argument that a winery that is performing better than expected has a positive effect on expenditure, falling short of these expectations will not harm this segment much. The result is opposite in the case of psychographic-based segments.

Given that the questionnaire was distributed only in Spanish, the respondents were Spanish, what might constitute a limitation of the sample.

\section{LIMITATIONS AND FUTURE RESEARCH}

Regarding limitation, although online surveys have been proven to be a more efficient, cheaper, and quicker way to gather information than face-to-face interviews, these surveys can introduce some bias derived from the self-selection of the interviewees. Particularly, our survey was conducted in Spanish and our sample does, therefore, not consider international tourists visiting Spanish wineries. Also, a broader variety of psychographic variables, such as attitudes, values, and lifestyles, could reflect the other dimensions of consumer behavior. As for future research lines, the simultaneous use of segment-based reference points and product-based reference points can be used to enrich the results. Determining which reference points (segment-based vs. product-based) have a better explanatory power would shed some light on the fact that both benchmarks can offer various perspectives, which entails that these two reference points can complement each other. 


\section{CONCLUDING REMARKS}

Although the relationship between visitor satisfaction and expenditure in wineries has been investigated in previous literature, the motivation of this study emerges from the lack of research that incorporates the paradigm of prospect theory into this satisfaction-expenditure relationship in wineries. We have unearthed relevant intricacies in this relationship and found that reference dependence is supported. Also, when reference points are based on psychographics, loss aversion is confirmed, while diminishing sensitivity is observed for losses only. Interestingly, when the reference points are obtained through demographics, loss aversion is reversed. Theoretical implications related to the way the satisfaction-expenditure relationship should be analyzed are pointed out, and managerial implications provide new angles as to the way wineries tackle visitor satisfaction and the differential effects of visitor characteristics-demographics vs psychographics—on expenditure. 


\section{REFERENCES}

Acevin (2018). "Informe de visitantes a bodegas y museos del vino asociados a las Rutas del Vino de España 2017”. Asociación Española de Pequeñas y Medianas Ciudades Vitivinícolas.[Report of visitors to wineries and wine museums associated with the Wine Routes of Spain 2017. Spanish Association of Small and Medium Wine Cities].Accessed: https://www.wineroutesofspain.com/bd/archivos/archivo873.pdf

Alonso,A., Fraser, R.A., \& Cohen, D.A. (2007). Does age matter? How age influences the winery experience. International Journal of Culture, Tourism and Hospitality Research,1(2),131-138.

Back,R.M., Bufquin,D., \& Park,J.Y. (2018). Why do they come back? The effects of winery tourists' motivations and satisfaction on the number of visits and revisit intentions. International Journal of Hospitality \& Tourism Administration,1-25,doi: 10.1080/15256480.2018.1511499.

Barth,S., \& Salazar,J. (2010). Wine Tourism and Consumer Behaviors Related to Wine Purchases, Journal of Tourism Insights, 11(2), doi, 0.9707/2328-0824.1001.

Bruwer,J., \& Alant,K. (2009). The hedonic nature of wine tourism consumption: an experiential view. International Journal of Wine Business Research,21(3):235-257.

Bruwer,J., \& Buller,C. (2012). Country-of-origin COO brand preferences and associated knowledge levels of Japanese wine consumers. Journal of Product and Brand Management,21(5),307-316.

Bruwer,J., Coode,M., Saliba,A., \& Herbst,F. (2013). Wine tourism experience effects of the tasting room on consumer brand loyalty. Tourism Analysis, 18(4),99-414.

Bruwer,J., Prayag,G., \& Disegna,M. (2018). Why wine tourists visit cellar doors: Segmenting motivation and destination image. International Journal of Tourism Research,20,355-366, doi, $0.1002 /$ jtr. 2187

Carlsen,J., \& Boksberger,P. (2015). Enhancing consumer value in wine tourism. Journal of Hospitality and Tourism Research,39(1),132-144.

Charters,S., \& Ali- Knight,J. (2002). Who is the wine tourist? Tourism Management,23(2),311319.

Chattopadhyay,M., \& Mitra,S.K. (2020). What Airbnb host listings influence peer-to-peer tourist accommodation price? Journal of Hospitality \& Tourism Research, 1096348020910211.

Cho,M., Bonn,M.A. \& Brymer,R.A. (2017), A constraint-based approach to wine tourism market segmentation, Journal of Hospitality \& Tourism Research,41(4),415-444.

Dawson,H., Holmes,M., Jacobs,H., \& Wade,R.I. (2011). Wine tourism: Winery visitation in the wine appellations of Ontario. Journal of Vacation Marketing, 17(3),37-246.

Del Chiappa, G., Napolitano,E., \& Atzeni,M. (2019). Perceived authenticity, satisfaction and behavioural intentions at wineries. Micro \& Macro Marketing,28(1),117-138.

Dodd, T., \& Bigotte,V. (1997). Perceptual differences among visitor groups to wineries. Journal of Travel Research,35(3),6-51.

Getz, D. (2000). Wine tourism: Management, Development \& Destinations. New York: Cognizant Communications.

Hall, C.M., Johnson,G., Cambourne,B., Macionis,N., Mitchell,R., \& Sharples,L. (2000).Wine tourism: An introduction. In C. M. Hall, L. Sharples, B. Cambourne, \& N. Macionis (Eds.) Wine tourism around the world: Development, management and markets (pp.1-24). London: Elsevier. 
Heckman, J.J. (1979). Sample selection bias as a specification error. Econometrica,47(1),153161.

Hojman, D.E., \& Hunter-Jones,P. (2012). Wine tourism: Chilean wine regions and routes. Journal of Business Research,65(1),13-21.

Hollebeek, L.D., Jaeger, S.R., Brodie, R.J., \& Balemi, . (2007). The influence of involvement on purchase intention for new world wine. Food Quality and Preferences, 18(8),1033-1049.

Kim, J.Y., \& Canina,L. (2015). An analysis of smart tourism system satisfaction scores: The role of priced versus average quality. Retrieved October 31, from Cornell University, School of Hotel Administration site: http://scholarship.sha.cornell.edu/articles/970

King,E.S., Johnson, T.E., Bastian, S.E.P., Osidacz,P., \& Francis,I.L. (2012). Consumer liking of white wines: Segmentation using self-reported wine liking and wine knowledge. International Journal of Wine Business Research, 24(1),33-46.

Kolyesnikova,N., Dodd,T., \& Laverie,D.A. (2007). Gratuity purchasing at wineries: An investigation of the determining factors. International Journal of Wine Business Research,19(4),239-256.

Lee,K., Madanoglu,M., Ha,I.S., \& Fritz,A. (2018). The impact of service quality and customer satisfaction on consumer spending in wineries. The Service Industries Journal,1-13.

Leri,I. \& Theodoridis,P. (2019). The effects of the winery visitor experience on emotions, satisfaction and on post-visit behavior intentions. Tourism Review. doi, 0.1108/TR-072018-0092

Lewis,P., and Thomas,H. (1990). The Linkage between Strategy, Strategic Groups, and Performance in the UK Retail Grocery Industry. Strategic Management Journal,11,385-97.

Marzo-Navarro,M. \& Pedraja-Iglesias,M. (2010). Are there different profiles of wine tourists? An initial approach. International Journal of Wine Business Research,22(4),349-361.

Marzo-Navarro,M. \& Pedraja-Iglesias,M. (2012). Critical factors of wine tourism: incentives and barriers from the potential tourist's perspective. International Journal of Contemporary Hospitality Management, 24(2), 312-334. Doi, 0.1108/09596111211206196

Mason,M.C., \& Paggiaro,A. (2012). Investigating the role of festivalscape in culinary tourism: The case of food and wine events. Tourism Management,33(6),1329-1336,

Mitchell,R., \& Hall, C.M. (2001a). The influence of gender and region on the New Zealand winery visit. Tourism Recreation Research,26(2),63-75.

Mitchell,R., \& Hall, C.M. (2001b). Lifestyle behaviors of New Zealand winery visitors: wine club activities, wine cellars and place of purchase. International Journal of Wine Marketing, 13(3),82-93.

Mitchell,R., \& Hall,C.M. (2004). The post-visit consumer behavior of New Zealand winery visitors. Journal of Wine Research,15(1),39-49.

Mitchell,R., \& Hall,C.M. (2006). Wine tourism research: the state of play. Tourism Review International,9(4),307-332.

Molina,A., Gómez,M., González-Díaz,B., \& Esteban,A. (2015). Market segmentation in wine tourism: strategies for wineries and destinations in Spain. Journal of Wine Research,26(3),192-224.

Nella,A., \& Christou,E. (2014). Segmenting wine tourists on the basis of involvement with wine. Journal of Travel and Tourism Marketing,31(7),783-798.

Neter,J., Wasserusan,W., \& Kutner,M. (1985). Applied linear statistical models: Regression analysis of variance and experimental design. Chicago: Irwin. 
Nicolau,J.L. (2008). Testing reference dependence, loss aversion and diminishing sensitivity in Spanish tourism. Investigaciones Económicas,32(2),231-255.

O'Neill,M., Palmer,A., \& Charters,S. (2002). Wine production as a service experience - the effects of service quality on wine sales. Journal of Services Marketing, 16(4),342-362.

OIV Report (2019), State of the Vitiviniculture World Market State of the Sector in 2018, International Organization of Vine and Wine, Retrieved by October 31 ${ }^{\text {st }}, 2019$, http://www.oiv.int/public/medias/6679/en-oiv-state-of-the-vitiviniculture-world-market2019.pdf

Park,J.Y., Bufquin,D., \& Back,R.M. (2019). When do they become satiated? An examination of the relationships among winery tourists' satisfaction, repeat visits and revisit intentions. Journal of Destination Marketing and Management,11,231-239.

Rahman,I., \& Reynolds,D. (2015). Wine: Intrinsic attributes and consumers' drinking frequency, experience, and involvement. International Journal of Hospitality Management,44,1-11,

Thanh,T. V., \& Kirova,V. (2018). Wine tourism experience: a netnographic study. Journal of Business Research, 83,30-37

Thomas,B.; Quintal,V.A. \& Phau, I. (2018). Wine tourist engagement with the winescape: scale development and validation, Journal of Hospitality \& Tourism Research,42(5),793-828.

UNWTO (2019). Tourism Highlights: 2019 Edition. Madrid: World Tourism Organization

Veres,D., Clark,H., \& Golbourne,D. (2008). Increasing the contribution of special events to Niagara's tourism industry. International Journal of Contemporary Hospitality Management,20,313-319.

Walasek,L., \& Stewart,N. (2015). How to make loss aversion disappear and reverse: Tests of the decision by sampling origin of loss aversion. Journal of Experimental Psychology: General, 144(1),7-11. http://dx.doi.org/10.1037/xge0000039

$\mathrm{Xu}, \mathrm{X}$. (2019). Examining the relevance of online customer textual reviews on hotels' product and service attributes. Journal of Hospitality \& Tourism Research,43(1),141-163.

Ye,B.H., Zhang,H.Q. \& Yuan,J. (2017). Intentions to participate in wine tourism in an emerging market: theorization and implications, Journal of Hospitality \& Tourism Research,41(8),1007-1031.

Yuan,J., Cai,L., Morrison, A., \& Linton, S. (2005). An analysis of wine festival attendees' motivations: a synergy of wine, travel and special events? Journal of Vacation Marketing, 11(1),1-58.

Zheng,H., Xu,B., Hao,L., \& Lin,Z. (2018). Reversed loss aversion in crowdsourcing contest. European Journal of Information Systems,27(4),434-448. 
Table 1. Descriptive statistics

\begin{tabular}{|c|c|c|}
\hline Variable & Mean/Proportion & SD \\
\hline \multicolumn{3}{|l|}{ Dependent variable } \\
\hline Expenditure & 17.67 & 20.51 \\
\hline Expenditure $(>0)$ & 30.06 & 18.51 \\
\hline \multicolumn{3}{|l|}{ Independent variables - main variables } \\
\hline Satisfaction with the staff & 5.76 & .990 \\
\hline Satisfaction with the winery facilities & 5.24 & 1.16 \\
\hline Satisfaction with the environment & 5.62 & 1.26 \\
\hline Satisfaction (average) & 5.54 & 0.93 \\
\hline \multicolumn{3}{|l|}{ Independent variables - control variables } \\
\hline I often attend wine tastings & 3.97 & 1.78 \\
\hline Wine culture should be promoted more intensely & 5.10 & 1.46 \\
\hline I read wine magazines & 4.26 & 2.00 \\
\hline I am interested in wine & 4.58 & 1.76 \\
\hline Interest in wine (average) & 4.47 & 1.51 \\
\hline I am a wine specialist & 3.32 & 1.68 \\
\hline I know different wine areas (protected designations of origin) & 4.78 & 1.42 \\
\hline I have a huge knowledge of the wine culture & 4.02 & 1.74 \\
\hline Knowledge of wine (average) & 4.04 & 1.34 \\
\hline Age 18-24 & 18.7 & \\
\hline Age 25-34 & 26.0 & \\
\hline Age $35-44$ & 31.4 & \\
\hline Age 45-54 & 15.0 & \\
\hline Age $>55$ & 8.9 & \\
\hline Gender (Female) & 48.7 & \\
\hline Monthly income & $€ 1637.7 *$ & 552.90 \\
\hline Income $<€ 900$ & 17.6 & \\
\hline Income $€ 900-1500$ & 26.0 & \\
\hline Income $€ 1501-2000$ & 26.0 & \\
\hline Income $€ 2001-2500$ & 17.6 & \\
\hline Income $>€ 2501$ & 12.9 & \\
\hline
\end{tabular}

* $\overline{\text { Obtained via midpoint coding by considering the average of each interval and the number of respondents assigned to each interval }}$. 
Table 2. Segments based on demographics

\begin{tabular}{ccccc}
\hline \hline No. of Segments & $\sigma^{2 *}$ & $\sigma^{2}(\mathbf{\%}) *$ & $\begin{array}{c}\text { Explained } \\
\text { Variance }\end{array}$ & $\Delta \sigma^{2 *}$ \\
\hline $\mathbf{1 0}$ & 399.10 & 21.87 & 1.72 & 78.13 \\
$\mathbf{9}$ & 430.48 & 23.59 & 2.39 & 76.41 \\
$\mathbf{8}$ & 474.05 & 25.98 & 2.39 & 74.02 \\
$\mathbf{7}$ & 517.63 & 28.37 & 4.36 & 71.63 \\
$\mathbf{6}$ & 597.10 & 32.72 & 4.55 & 67.28 \\
$\mathbf{5}$ & 680.21 & 37.28 & 5.27 & 62.72 \\
$\mathbf{4}$ & 776.45 & 42.55 & 7.04 & 57.45 \\
$\mathbf{3}$ & 904.89 & 49.59 & 14.24 & 50.41 \\
$\mathbf{2}$ & 1164.70 & 63.83 & 36.17 & 36.17 \\
$\mathbf{1}$ & 1824.63 & 100.00 & 0.00 & 0.00 \\
\hline \hline
\end{tabular}

*Intra-group variance. 
Table 3. Segments based on psychographics

\begin{tabular}{ccccc}
\hline \hline \multirow{2}{*}{ No. of Segments } & $\sigma^{2 *}$ & $\sigma^{\mathbf{2}}(\mathbf{\%})^{*}$ & $\begin{array}{c}\text { Explained } \\
\text { Variance }\end{array}$ & $\Delta \sigma^{2 *}$ \\
\hline $\mathbf{1 0}$ & 139.89 & 8.00 & 0.95 & 92.00 \\
$\mathbf{9}$ & 156.47 & 8.94 & 0.98 & 91.06 \\
$\mathbf{8}$ & 173.66 & 9.93 & 1.21 & 90.07 \\
$\mathbf{7}$ & 194.79 & 11.14 & 1.45 & 88.86 \\
$\mathbf{6}$ & 220.15 & 12.58 & 2.58 & 87.42 \\
$\mathbf{5}$ & 265.34 & 15.17 & 3.89 & 84.83 \\
$\mathbf{4}$ & 333.45 & 19.06 & 7.25 & 80.94 \\
$\mathbf{3}$ & 460.21 & 26.31 & 9.58 & 73.69 \\
$\mathbf{2}$ & 627.72 & 35.88 & 64.12 & 64.12 \\
$\mathbf{1}$ & 1749.30 & 100.00 & 0.00 & 0.0 \\
\hline \hline *Intra-group variance. & & &
\end{tabular}

*Intra-group variance. 
Table 4. Average satisfaction (expected values) for demographic and psychographic comparison groups

\begin{tabular}{c|cc|cc}
\hline \hline Segment & Demographic-based segmentation & Segment size & Psychographic-based segmentation & Segment size \\
\hline 1 & 5.75 & 119 & 5.62 & 123 \\
2 & 5.72 & 42 & 5.88 & 74 \\
3 & 5.6 & 91 & 5.37 & 75 \\
4 & 5.68 & 46 & 5.36 & 87 \\
5 & 5.23 & 88 & 5.46 & 68 \\
6 & 5.14 & 41 & & \\
\hline \hline
\end{tabular}


Table 5. Effects of visitor satisfaction on winery visitor expenditure with reference dependence

\begin{tabular}{lcccccccc}
\hline \hline & \multicolumn{2}{c}{ Model 1 } & \multicolumn{2}{c}{ Model 2 } & \multicolumn{2}{c}{ Model 3 } & \multicolumn{2}{c}{ Model 4 } \\
\cline { 2 - 8 } & Parameter & SD & Parameter & SD & Parameter & SD & Parameter & SD \\
\hline STGain (psychographics) & -8.342 & 9.674 & -12.164 & 10.056 & & & & \\
STLoss (psychographics) & $11.176^{\mathrm{b}}$ & 5.143 & $14.216^{\mathrm{a}}$ & 5.365 & & & & \\
STGain $^{2}$ (psychographics) & 7.417 & 7.634 & 10.786 & 7.712 & & & & \\
STLoss ${ }^{2}$ (psychographics) & $3.866^{\mathrm{c}}$ & 2.259 & $4.886^{\mathrm{b}}$ & 2.387 & & & & \\
STGain (demographics) & & & & & $14.747^{\mathrm{b}}$ & 6.786 & $13.011^{\mathrm{c}}$ & 8.041 \\
STLoss (demographics) & & & & & -1.062 & 4.214 & 2.980 & 4.460 \\
STGain ${ }^{2}$ (demographics) & & & & & -8.530 & 5.510 & -6.645 & 6.227 \\
STLoss ${ }^{2}$ (demographics) & & & & & -1.478 & 2.729 & -0.248 & 2.788 \\
Interest in wine & $6.453^{\mathrm{a}}$ & 0.679 & & & $6.030^{\mathrm{a}}$ & 0.709 & & \\
Knowledge of wine & & & $6.056^{\mathrm{a}}$ & 0.727 & & & $5.197^{\mathrm{a}}$ & 0.733 \\
Age 18-34 & 0.829 & 2.088 & -1.553 & 2.281 & -0.288 & 2.139 & -2.863 & 2.357 \\
Age $>35$ & -0.393 & 2.632 & 0.143 & 2.851 & -0.386 & 2.598 & 0.062 & 2.792 \\
Gender & $5.619^{\mathrm{a}}$ & 1.875 & $5.062^{\mathrm{b}}$ & 1.991 & $5.657^{\mathrm{a}}$ & 1.921 & $5.114^{\mathrm{b}}$ & 2.028 \\
Income $<€ 1501$ & -3.120 & 2.671 & -3.712 & 2.753 & -2.548 & 2.667 & -3.420 & 2.733 \\
Income $>€ 2001$ & 1.289 & 2.824 & -0.245 & 2.947 & 1.608 & 2.866 & -0.084 & 2.983 \\
Constant & -0.093 & 5.299 & 7.016 & 5.065 & -2.814 & 4.808 & 6.079 & 4.635 \\
\hline R-squared & 0.343 & & 0.273 & & 0.341 & & 0.269 & \\
Adjusted R-squared & 0.316 & & 0.243 & & 0.314 & & 0.238 & \\
F-statistic & $12.540^{\mathrm{a}}$ & & $9.006^{\mathrm{a}}$ & & $12.417^{\mathrm{a}}$ & & $8.825^{\mathrm{a}}$ & \\
\hline \hline
\end{tabular}

$\mathrm{a}=\mathrm{p}<0.01 ; \mathrm{b}=\mathrm{p}<0.05 ; \mathrm{c}=\mathrm{p}<0.1$ 